\title{
Prevalence of chimerism after non-myeloablative hematopoietic stem cell transplantation
}

\author{
Prevalência do quimerismo após transplante de células hematopoiéticas não-mieloablativo \\ Azulamara da Silva Ruiz', Maria de Lourdes Ferrari Chauffaille", Solivanda Trindade Alves"II, José Salvador Rodrigues de Oliveira"l \\ Division of Hematology and Transfusion Medicine, Universidade Federal de São Paulo - Escola Paulista de Medicina (Unifesp-EPM), São Paulo, Brazil
}

\section{KEY WORDS:}

Variable number of tandem

\section{repeats.}

Hematologic neoplasms. Bone marrow transplantation. In situ hybridization, fluorescence. Chimerism.

Leukemia.

\section{PALAVRAS-CHAVE:}

Repetições mini-satélites.

Neoplasia hematológicas.

Transplante de medula óssea.

Hibridização in situ fluorescente.

Quimerismo.

Leucemia.

\begin{abstract}
CONTEXT AND OBJECTIVE: Non-myeloablative hematopoietic stem cell transplantation (NMA-HSCT) is performed in onco-hematological patients who cannot tolerate ablative conditioning because of older age or comorbidities. This approach does not completely eliminate host cells and initially results in mixed chimerism. Long-term persistence of mixed chimerism results in graft rejection and relapse. Involvement of graft-versus-host disease is concomitant with complete chimerism and graft-versus-tumor effect. The aim of this study was to evaluate the prevalence of chimerism in onco-hematological patients who underwent NMA-HSCT.

DESIGN AND SETIING: Observational clinical study on chimerism status after human leukocyte antigen-identical NMA-HSCT at the Discipline of Hematology and Hemotherapy of Universidade Federal de São Paulo.

METHODS: We sequentially analyzed the amplification of APO-B, D1S80, DxS52, FVW, 33.6, YNZ-2 and H-ras primers using variable number of tandem repeats (VNTR) on 17 pairs and fluorescent in situ hybridization (FISH) with the XY probe and SRY primer on 13 sex-unmatched pairs.

RESULTS: The informativeness of the primers using VNTR was $60 \%$ for APO-B, $75 \%$ D1S80, 36\% DxS52, 14\% FVW, $40 \%$ YNZ-22 and $16 \%$ H-ras. The SRY primer was informative in female receptors with male donors. The XY-FISH method was informative in $100 \%$ of the sex-unmatched pairs.

CONCLUSION: These methods were sensitive and informative. In VNTR, the association of APO-B with D1S 80 showed $88 \%$ informativeness. The quantitative FISH method was more sensitive, but had the disadvantage of only being used for sex-unmatched pairs.
\end{abstract}

\section{RESUMO}

CONTEXTO E OBJETIVO: 0 transplante de células hematopoiéticas não-mieloablativo é realizado em pacientes com doenças onco-hematológicas que não suportam condicionamentos ablativos devido à elevada idade ou ao acometimento por comorbidades. Esta abordagem não elimina completamente as células do hospedeiro, resultando, inicialmente, em quimerismo misto. A persistência do quimerismo misto na evolução de longo prazo resulta na rejeição ao enxerto e recaída. 0 acometimento pela doença do enxerto contra hospedeiro é concomitante ao quimerismo completo e ao efeito enxerto versus tumor. 0 objetivo deste estudo foi avaliar a prevalência do quimerismo em doenças onco-hematológicas tratadas com o transplante não-mieloablativo de células hematopoiéticas.

TIPO DE ESTUDO E LOCAL: Estudo clínico observacional do estado de quimerismo após transplante antígenos leucocitários humanos-idêntico nãomieloabaltivo realizado na Disciplina de Hematologia e Hemoterapia da Universidade Federal de São Paulo.

MÉTOD0S: Analisamos sequencialmente a amplificação dos primers APO-B, D1S80, DxS52, FVW, 33,6, YNZ-22, H-ras pelo VNTR (variable number of tandem repeats) em 17 pares e FISH (fluorescent in situ hybridization) pela sonda XY e do primer SRY em 13 pares de não relacionados a sexo. RESULTADO: A informatividade dos primers pelo VNTR foi de 60\% para APO-B; 75\% D1S80; 36\% DxS52; 14\% FVW; $40 \%$ YNZ-22 e 16\% H-ras. 0 primer SRY foi informativo em receptores femininos com doadores masculinos. 0 método XY-FISH foi informativo em $100 \%$ dos pares de não relacionado a sexo. CONCLUSÃ0: Estes métodos foram sensiveis e informativos. No VNTR, a associação do APO-B com D1S80 mostrou 88\% de informatividade. 0 FISH, método quantitativo, foi mais sensível, porém com desvantagem de ser usado somente nos pares não relacionados a sexo.
'BSc. Postgraduate student, Division of Hematology and Transfusion Medicine, Universidade Federal de São Paulo - Escola Paulista de Medicina (Unifesp-EPM), São Paulo, Brazil. "MD, PhD. Associate professor, Department of Medicine. Division of Hematology and Transfusion Medicine, Universidade Federal de São Paulo - Escola Paulista de Medicina (UnifespEPM), São Paulo, Brazil.

"'MD. Physician in the Division of Hematology and Transfusion Medicine, Hospital Santa Marcelina, São Paulo, Brazil.

"MD, PhD. Associate professor, Department of Medicine, Division of Hematology and Transfusion Medicine, Universidade Federal de São Paulo - Escola Paulista de Medicina (Unifesp-EPM); and coordinator of the Division of Hematology and Transfusion Medicine, Hospital Santa Marcelina, São Paulo, Brazil. 


\section{INTRODUCTION}

Non-myeloablative hematopoietic stem cell transplantation (NMAHSCT) is indicated for patients who cannot tolerate conventional ablative regimens because of older age or the presence of comorbidities. Non-myeloablative regimens do not completely eliminate the cells from the host. Initially, both donor and recipient cells are present, a condition known as mixed chimerism. This state of mixed chimerism is subsequently converted into complete chimerism through infusions of the donor's lymphocytes or manipulation of immunosuppression during the post-transplant period. The persistence of mixed chimerism, regardless of whether ablative or non-myeloablative conditioning is performed, results in relapses. ${ }^{1-3}$

Host involvement through graft-versus-host disease generally occurs concurrently with complete chimerism. Successful clinical manipulation of graft-versus-host disease is desirable because it is usually associated with eradication of the underlying disease through the graft-versus-tumor effect. Full chimera means complete chimerism of immune and hematopoietic cells, consisting of $100 \%$ donor cells, and is the main factor for achieving definitive cure.

After transplantation, chimerism analysis provides important clinical information, such as in relation to total or partial reconstitution of the immune system and hematopoiesis in grafted cells. Evaluations on the polymerase chain reaction (PCR), markers for polymorphism loci of variable number tandem repeats (VNTR) and short tandem repeats (STR) inform the degree of chimerism in sex-matched and sexunmatched transplants. These techniques allow assessment of both pairs, or differentiation between donor and host deoxyribonucleic acid (DNA). The fundamental principle of the VNTR and STR techniques is that they distinguish DNA patterns between the donor and host by means of a panel of specific primers prior to transplantation. Once such a panel has been established, post-transplant monitoring of chimerism becomes applicable. The intensity of chimerism that is found depends on identifying and measuring genetic markers that vary between the donor and host. ${ }^{3,4}$

The conventional cytogenetic analysis that is classically used to assess chimerism following sex-unmatched transplantation is inappropriate because only small numbers of cells undergoing mitosis are available after transplantation. This difficulty is explained by the hypocellularity of the bone marrow, which can persist for months after the infusion, as well as by difficulties in inducing mitosis using the usual mitogens. ${ }^{1,5,6}$

Mixed chimerism is defined as the presence of donor cells in proportions between 2.5 and $97 \%$, within the cellular context of host hematopoiesis. XY fluorescent in situ hybridization (FISH) is used on sexunmatched pairs as a simple quantitative method for investigating this, and is applicable even when there are low numbers of cells in marrow samples. ${ }^{7}$ The XY probe allows two different colors to be viewed. ${ }^{8}$ Its resolution is high, but it can only be applied in cases of sex-unmatched transplants. ${ }^{6}$ The SRY marker can also be used to quantify the presence of the $\mathrm{Y}$ chromosome in sex-unmatched pairs. ${ }^{9-11}$

NMA-HSCT can be performed with the patient either in the ward or in the outpatient clinic. ${ }^{12-14}$ The classical indications for non-myeloablative regimens are indolent disease such as chronic myeloid leuke- mia, low-grade non-Hodgkin's lymphomas, chronic lymphocytic leukemia and mantle cell lymphoma. ${ }^{14-19}$ These diseases are intensely sensitive to the graft-versus-host effect. The diseases that present intermediate sensitivity to this immunological effect are acute myeloid leukemia, intermediate and high-grade non-Hodgkin's lymphomas, multiple myeloma and Hodgkin's lymphoma. ${ }^{12,14-19}$

\section{OBJECTIVE}

The aim of this study was to evaluate the prevalence of chimerism in 21 patients with onco-hematological diseases who underwent NMAHSCT and the resolution of different techniques.

\section{MATERIALS AND METHODS}

\section{Patient sample}

This was a case series comprising 21 patients ( 14 males and seven females), with a mean age of 47 years and an average of two years of disease evolution prior to the transplantation. Three of the patients had undergone autologous stem cell transplantation previously. Two of the patients underwent transplantation presenting with positive minimal residual disease, seven with progressive disease and two with refractory disease.

All of the patients were included consecutively in this study, without selection, between February 2003 and January 2006. Twelve patients were from Hospital Santa Marcelina and nine from Hospital São Paulo. Two donor/recipient sex-unmatched patients were subsequently included for XY-FISH analyses in 2006. All of the patients underwent matched HLA (human leukocyte antigen)-identical NMA-HSCT. The non-myeloablative conditioning regimen protocols included 14 of the 21 patients, who used fludarabine in their regimens. ${ }^{13,15-19}$ Six multiple myeloma patients received melphalan doses lower than $140 \mathrm{mg} / \mathrm{m}^{2}$ and one received $120 \mathrm{mg} / \mathrm{m}^{2}$ plus $120 \mathrm{mg} / \mathrm{m}^{2}$ of cyclophosphamide as their conditioning. ${ }^{15}$ The prophylaxis for graft-versus-host disease consisted of cyclosporine-A plus methotrexate for all settings. ${ }^{17,18}$ The infectious disease prophylaxis that was used followed the universally known protocols. ${ }^{15-19}$ This study was previously approved by the Research Ethics Committees of both institutions (Protocol numbers 18/2005 and 1162/03 for Hospital Santa Marcelina and Hospital São Paulo, respectively) and an informed consent statement was signed by all patients and their donors.

Table 1 presents the characteristics of the patient sample: numbers of patients, clinical situation (underlying diseases and patients' clinical situation before transplantation), recipient and donor genders, comorbidities, age at the time of transplantation and duration of illness until the transplantation was performed.

\section{Chimerism prevalence evaluation}

This was a cross-sectional prevalence study on chimerism. We used the VNTR technique on 17 pairs and FISH with XY probe on sex-unmatched pairs. The chimera evaluations were done sequentially prior to transplantation in order to define the different primer pairs between the donor and recipient. DNA amplification was done on the patients on days $30,60,120,180$ and 360, and subsequently, much later af- 
Table 1. Characteristics of patient sample: numbers of patients, underlying disease, age at the time of transplantation, recipient and donor genders, comorbidities and duration of illness until transplantation was performed

\begin{tabular}{|c|c|c|c|c|c|c|}
\hline Patient & Disease & Age (years) & Sex R/D & Pre-HSCT status & Comorbidities & Evolution (months) \\
\hline 4 & MM & 28 & $\mathrm{M} / \mathrm{F}$ & PD, MM-IIIA & - & 10 \\
\hline 8 & MM & 56 & $M / F$ & PD, post-AHSCT, MM-IIIA & - & 44 \\
\hline 10 & MM & 53 & $M / F$ & MM-IIIA & CRF & 18 \\
\hline 12 & MM & 53 & $\mathrm{~F} / \mathrm{M}$ & MM-IIIA & OB & 12 \\
\hline 17 & MM & 46 & $\mathrm{M} / \mathrm{M}$ & PD, MM-IIIA & - & 8 \\
\hline 18 & MM & 48 & $\mathrm{M} / \mathrm{M}$ & $2^{\text {nd }} P R, M M-I I B B$ & - & 5 \\
\hline 09 & MM & 49 & $\mathrm{~F} / \mathrm{M}$ & PD, post- AHSCT, MM-IIIA & - & 69 \\
\hline 15 & MM & 42 & $\mathrm{~F} / \mathrm{F}$ & PD, MM-IIIA & DVT-LL & 11 \\
\hline 14 & $\mathrm{C}-\mathrm{CML}$ & 39 & $\mathrm{~F} / \mathrm{F}$ & C-CML & SKS, CRRF & 36 \\
\hline 3 & MDS & 55 & $\mathrm{M} / \mathrm{F}$ & 7q-(T-RAEB), MDS & $\mathrm{CA}-\mathrm{HCV}$ & 6 \\
\hline 6 & AML-M3 & 33 & $\mathrm{~F} / \mathrm{M}$ & MRD, AML-M3 & CCF* & 18 \\
\hline 7 & AML-M2 & 20 & $\mathrm{M} / \mathrm{F}$ & Recurrence post-AHSCT, AML-M2 & CCF* & 8 \\
\hline 13 & MDS & 63 & $\mathrm{M} / \mathrm{F}$ & 5q-RAEB, MDS & $\mathrm{DM}, \mathrm{HT}$ & 30 \\
\hline 16 & AML & 59 & $\mathrm{M} / \mathrm{M}$ & $2^{\text {nd }} \mathrm{MDS}, 1^{\text {st }} \mathrm{CR}$, AML & $\mathrm{CCC}, \mathrm{HT}$ & 13 \\
\hline 21 & $\mathrm{C}-\mathrm{CML}$ & 53 & $\mathrm{M} / \mathrm{M}$ & $\mathrm{C}-\mathrm{CML}$ & CCF & 24 \\
\hline 1 & CLL & 47 & $\mathrm{M} / \mathrm{F}$ & Binet C, MRD, CLL & - & 16 \\
\hline 2 & $\mathrm{FL}$ & 44 & $\mathrm{M} / \mathrm{F}$ & Relapsed IVB, FL-GIII, & - & 36 \\
\hline 5 & $\mathrm{NHL}$ & 38 & $\mathrm{M} / \mathrm{F}$ & RD rich in T cell, IVB, DLBCL & AC, HPV & 33 \\
\hline 11 & $\mathrm{NHL}$ & 58 & $\mathrm{~F} / \mathrm{M}$ & DP, post-AHSCT, MM-IIIB, GII, FL & COPD & 28 \\
\hline 19 & CLL, RS & 53 & $\mathrm{M} / \mathrm{M}$ & DP, CLL, RS & $\begin{array}{l}\text { CA-HBV, } \\
\text { DM, HT, OB }\end{array}$ & 96 \\
\hline 20 & NHL & 48 & $\mathrm{~F} / \mathrm{F}$ & MF & HT & 10 \\
\hline
\end{tabular}

IVB = stage IVB (Ann Arbor), bone marrow or liver disease infiltration; AML-M3 = promyelocytic acute myeloid leukemia; AML-M2 = acute myeloid leukemia with differentiation (FAB-M2); RAEB = refractory anemia with excess of

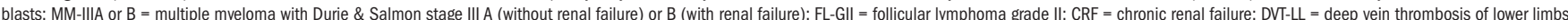
$\mathrm{Sex} R / D=$ sex of recipient/donor; $M=$ Male; $F=$ Female; $P D=$ progressive disease; $R D=$ refractory disease; $A H S C T=$ autologous hematopoietic stem cell transplantation; $O B=$ obesity; $M R D=$ minimal residual disease; $C R=$ complete remission; $\mathrm{PR}=$ partial remission; $\mathrm{CCF}=$ congestive cardiac failure, $\mathrm{CCF} *=$ congestive cardiac failure secondary to use of anthracyclines; $\mathrm{CA}-\mathrm{HBV}=\mathrm{chronic}$ active hepatitis $\mathrm{B}$ virus, $\mathrm{CA}-\mathrm{HCV}=$ chronic active hepatitis $\mathrm{C}$ virus; $\mathrm{HT}=$ hypertension; $\mathrm{CCC}=$ chronic calculous cholecystitis; $\mathrm{DM}=$ diabetes mellitus; $\mathrm{SKS}=$ severe kyphoscoliosis; $\mathrm{CRRF}=$ chronic restrictive respiratory failure; $\mathrm{COPD}=$ chronic obstructive pulmonary disease; $\mathrm{FL}=$ follicular lymphoma; $\mathrm{DLBCL}=$ diffuse large $\mathrm{B}$ cell lymphoma; $\mathrm{MF}=$ mycosis fungoides; $\mathrm{MDS}=$ myelodysplastic syndrome; $\mathrm{AC}=$ alcoholic cirrhosis; $\mathrm{RS}=$ Richter syndrome; $\mathrm{HPV}=$ herpes papillomavirus, $\mathrm{C}-\mathrm{CML}=\mathrm{chronic}$ phase of chronic myelogenous leukemia; NHL = non-Hodgkin's lymphoma; CLL = chronic lymphocytic leukemia.

ter transplantation (+1200 days), on two patients. The results from the VNTR technique were correlated with those from FISH.

We used the VNTR technique to analyze the DNA obtained from the total peripheral blood leukocytes of the donor and recipients. Markers were selected based on their characteristics, degree of resolution or presence of polymorphism in multiple alleles, with homogeneous distribution frequency in populations previously studied ${ }^{3,6,18-31}$ and consequently a high degree of heterozygosity (Table 2). The SRY marker was chosen for examining transplantations from sex-unmatched donors, in order to determine whether the $\mathrm{Y}$ chromosome was present or absent. ${ }^{10,11}$ XY-FISH was performed on total bone marrow cells in the first and final evaluation of chimerism after transplantation from sexunmatched donors. ${ }^{8}$

DNA from recipients and donors was extracted using the Perfect gDNA Blood Mini-isolation kit (Eppendorf, Germany). ${ }^{22}$ It was amplified using the polymerase chain reaction (PCR) technique, by means of a thermocycler (Perkin Elmer 9700), for eight pairs of specific primers for each sequence. The characteristics of the chromosomal locations, base pair sequences and sizes of the amplified fragments are shown in Table 3 and the amplification conditions are shown in Table 4.

\section{XY-FISH}

The XY-FISH method was carried out using fresh material. We collected 3 to $5 \mathrm{ml}$ of bone marrow samples into syringes containing so-
Table 2. Markers according to amplification and resolution

\begin{tabular}{lcc}
\hline Marker & DNA amplification & Resolution \\
\hline AP0-B & $16 / 17(94 \%)$ & $10 / 16(62.5 \%)$ \\
\hline DS180 & $15 / 17(88 \%)$ & $10 / 15(75 \%)$ \\
\hline DxS52 & $11 / 17(64 \%)$ & $4 / 11(36 \%)$ \\
\hline FVW & $14 / 17(82 \%)$ & $2 / 14(14 \%)$ \\
\hline 33.6 & $10 / 17(58 \%)$ & $4 / 10(40 \%)$ \\
\hline YNZ-22 & $15 / 17(88 \%)$ & $7 / 15(47.6 \%)$ \\
\hline H-ras & $6 / 17(35 \%)$ & $1 / 6(16.6 \%)$ \\
\hline All markers & $17 / 17(100 \%)$ & $16 / 17(94 \%)$ \\
\hline
\end{tabular}

dium heparin. We then removed the leukocyte layer, which had been fixed in Carnoy's solution, and subsequently prepared microscope slides. These were denatured and hybridized in accordance with the protocol from the probe manufacturer (Vysis, Inc, United States). The slides were evaluated under an epifluorescence microscope with diamidinophenylindole (DAPI), fluorescein isothiocyanate (FITC) and rhodamine filters. The images were captured using the MacProbe 4.4 computer software (PowerGene System, Applied Imaging Corporation, United States) and scanned. The red (rhodamine) signal corresponded to the region of the $\mathrm{Y}$ chromosome and green (fluorescein) signal to the region of the $\mathrm{X}$ chromosome. Cells with two green signals were interpreted as female $(\mathrm{XX})$ and cells with one green and one red signal, as male $(\mathrm{XY}){ }^{8}$ 
Table 3. Primer sequences used in variable number of tandem repeats (VNTR) technique

\begin{tabular}{|c|c|c|c|c|}
\hline Primer & Chromosome location & Primer sequence & Product (base pairs) & Reference \\
\hline \multirow{2}{*}{ APO-B } & \multirow{2}{*}{$2 p 23-p 24$} & 5' ATG GAA ACG GAG AAA TTA TG 3' & \multirow{2}{*}{500 to 900} & \multirow{2}{*}{21} \\
\hline & & 5' СCT TCT CAC TTG GCA AAT AC 3' & & \\
\hline \multirow{2}{*}{ D1S80 } & \multirow{2}{*}{$1 p 35-p 36$} & 5' GAA ACT GGC CTC AAC ACT GCC CGC C 3' & \multirow{2}{*}{250 to 650} & \multirow{2}{*}{25} \\
\hline & & 5' GTC TाC TTG GAG GCA CGT GCC ССT T 3' & & \\
\hline \multirow{2}{*}{ DxS52 } & \multirow{2}{*}{$\mathrm{Xq} 26-\mathrm{q} 28$} & 5' CGA AGA GTG AAG TGC ACA GG 3' & \multirow{2}{*}{650 to 3000} & \multirow{2}{*}{23} \\
\hline & & 5' CAC AGT CT TAT TCT TCA GCG 3' & & \\
\hline \multirow{2}{*}{ FVW } & \multirow{2}{*}{$12 \mathrm{p} 13-3$} & 5' AGC TAT ATA TCT ATT TAT CAT 3' & \multirow{2}{*}{300 to 700} & \multirow{2}{*}{26} \\
\hline & & 5' ACA TAC ATA CAT AGA TAT AGG 3' & & \\
\hline 33.6 & $1 q$ & $\begin{array}{l}\text { 5' TGT GAG TAG AGG AGA CCT CAC 3' } \\
\text { 5'AAA GAC CAC AGA GTG AGG AGC 3' }\end{array}$ & 500 to 1000 & 27 \\
\hline H-ras & $11 \mathrm{p} 15.5$ & $\begin{array}{l}\text { 5' TTG GGG GAG AGC TAG CAG GG 3' } \\
\text { 5' СCT CCT GCA CAG GGT CAC CT 3' }\end{array}$ & 1000 to 2600 & 27 \\
\hline YNZ-22 & $17 \mathrm{p} 13.3$ & $\begin{array}{c}\text { 5' GGT CGA AGA GTG AAG TGC ACA G 3' } \\
\text { 5' GCC CCA TGT ATC TTG TGC AGT G 3' }\end{array}$ & 200 to 2000 & 27 \\
\hline SRY & $\mathrm{Y}$ & $\begin{array}{c}\text { 5' TCG CGA TTA AGT CAA ATT CGC 3' } \\
\text { 5' CCC CCT AGT ACC CTG ACA ATG TAT T 3' }\end{array}$ & 136 & 24 \\
\hline
\end{tabular}

Table 4. Conditions for primer amplification

\begin{tabular}{|c|c|c|c|c|}
\hline Marker & Denaturing & Girdling/extension (temperature, time, number of & & Reference \\
\hline APO-B & $94{ }^{\circ} \mathrm{C}, 1 \mathrm{~min}$ & $58^{\circ} \mathrm{C}(6 \mathrm{~min})$ & $\times 26$ & 28 \\
\hline D1S80 & $94^{\circ} \mathrm{C}, 1 \mathrm{~min}$ & $65^{\circ} \mathrm{C}(1 \mathrm{~min}) ; 70^{\circ} \mathrm{C}(5 \mathrm{~min})$ & $\times 28$ & 29 \\
\hline DxS52 & $94^{\circ} \mathrm{C}, 20 \mathrm{sec}$ & $55^{\circ} \mathrm{C}(30 \mathrm{sec}) ; 74^{\circ} \mathrm{C}(20 \mathrm{sec}) ;$ final $74^{\circ} \mathrm{C}(5 \mathrm{~min})$ & $\times 24$ & 23 \\
\hline FVW & $94^{\circ} \mathrm{C}, 20 \mathrm{sec}$ & $48^{\circ} \mathrm{C}(20 \mathrm{sec}) ; 72^{\circ} \mathrm{C}(20 \mathrm{sec})$ & $\times 30$ & 26 \\
\hline 33.6 & $95^{\circ} \mathrm{C}, 1 \mathrm{~min}$ & $60^{\circ} \mathrm{C}(45 \mathrm{sec}) ; 72{ }^{\circ} \mathrm{C}(1 \mathrm{~min}) ; 72^{\circ} \mathrm{C}(10 \mathrm{~min})$ & $\times 35$ & 22 \\
\hline H-ras & $94{ }^{\circ} \mathrm{C}, 5 \mathrm{~min}$ & $\begin{array}{c}95^{\circ} \mathrm{C}(1 \mathrm{~min}) ; 64^{\circ} \mathrm{C}(2 \mathrm{~min}) ; 72^{\circ} \mathrm{C}(6 \mathrm{~min}) \\
64^{\circ} \mathrm{C}(2 \mathrm{~min}) ; 72^{\circ} \mathrm{C}(10 \mathrm{~min})\end{array}$ & $\begin{array}{l}x 20 \\
\times 01\end{array}$ & 30 \\
\hline YNZ-22 & $95^{\circ} \mathrm{C}, 1 \mathrm{~min}$ & $60{ }^{\circ} \mathrm{C}(45 \mathrm{sec}) ; 72{ }^{\circ} \mathrm{C}(1 \mathrm{~min}) ; 72{ }^{\circ} \mathrm{C}(10 \mathrm{~min})$ & $\times 30$ & 22 \\
\hline SRY & $95^{\circ} \mathrm{C}, 10 \mathrm{~min}$ & $\begin{array}{l}95^{\circ} \mathrm{C}(15 \mathrm{sec}) ; 60^{\circ} \mathrm{C}(1 \mathrm{~min}) ; 72{ }^{\circ} \mathrm{C}(1 \mathrm{~min}) ; \\
\text { final } 72{ }^{\circ} \mathrm{C}(7 \mathrm{~min})\end{array}$ & $x 50$ & 24 \\
\hline
\end{tabular}

\section{RESULTS}

The VNTR technique was evaluated for 17 of the 21 patients. Four patients (\# 1, 2, 9 and 13) were only analyzed using the FISH method with XY probe. Among these four, cases 1 and 2 were analyzed 1200 days after the transplant. Case 9 was analyzed on days 60 and 360, and case 13 only on day 360. Cases 1 and 2 did not form part of the first period of this study and, in cases 9 and 13, no donor/recipient DNA analysis was obtained prior to transplantation, but in all these cases, the probe evaluated using XY-FISH documented complete chimerism. Even though these cases were not evaluated using the VNTR technique prior to transplantation, the complete chimerism found using the XY probe was confirmed by the SRY marker. The other sequence primers were found to be the following after transplantation: APO-B (cases 1, 2, 9 and 13), D1S80 (1, 2, 9 and 13), FWF (1 and 2), 33.6 (1 and 2), YNZ-22 (1, 2, 9 and 13), DxS52 (9) and H-ras (9).

A panel of markers consisting of APO-B, D1S80, YNZ-22, 33.6, DxS52, FVW, H-ras and SRY was used for the other 17 patients and the results obtained are described below.

Case 3 was an extension of DNA fragments that were identical for recipient and donor, to the APO-B, D1S80, DxS52, FWF and 33.6 markers. The donor and recipient bands for the YNZ-22 and H-ras markers failed to be obtained. A review using XY-FISH on day 30, showed mixed chimerism with XX cells accounting for $85 \%$. The donor for this particular patient was his mother.

Evaluation of the product from APO-B showed results in 16 cases (94\%), with information only on 10/16 patients (62.5\%). Cases 5, 6, $8,10,12,14,16,17$ and 22 showed different bands for these markers. It should be noted that patients 5, 16 and 21 only showed the APO-B marker through the VNTR technique (Table 2).

With the D1S80 marker, amplification occurred in relation to 15 patients (88\%); but information was found relating to $10 / 15(75 \%)$. For 5/17 (29\%), informative bands were present using the APO-B and D1S80 primers (cases 6, 8, 12, 14 and 17). On the other hand, regarding the panel composed only of the D1S80 and APO-B primers, resolution of chimerism occurred in relation to $15 / 17$ pairs (88\%). Only cases 3 and 20 showed no information relating to either of these two markers.

With the YNZ-22 marker, amplification was observed in relation to $15 / 17$ (88\%), but information was seen relating to $7 / 15$ (47.6\%). Patients 4, 6, 8, 10,11, 12 and 18 showed information with this marker. Case 18 was also evaluated using the STR primer (not shown), presenting complete chimerism through both methods at the same time.

Using the DxS52 marker, amplification showed a DNA product for $11 / 17$ patients $(64 \%)$, but information relating to this marker 
was seen in only four pairs (36\%): patients 4, 7, 11 and 19. With the FVW marker, amplification was seen in relation to $14 / 17$ (82\%), but information from this marker was documented in only two patients (14\%): cases 4 and 7 . Using the 33.6 marker, amplification was seen in relation to $10 / 17(58 \%)$ and there was pretransplantation information for 4/10 (40\%). Cases 7, 10, 12 and 20 presented resolution with this marker. It should be noted that case 20 only had the 33.6 primer as a marker.

Case 7 showed mixed chimerism documented using XY-FISH, with only $34 \%$ of the cells coming from the donor. This finding was confirmed using the D1S80, DxS52 and 33.6 primers. With the FVW marker, there was no grafting, and this was a different result. The interpretation was that this was mixed chimerism due to the other primers. On day 90, this patient presented molecular relapse, which was confirmed by information from all of the primers investigated. It should be noted that no acute or chronic graft-versus-host disease involvement was seen in this patient. Hematological relapse occurred 120 days after transplantation (Figures 1).

XY-FISH analysis on day 30 showed that $99 \%$ of the cells were from the donor in cases 4 and 10 and $97 \%$ in cases 5 and 12. Analysis using the VNTR technique concomitantly showed that case 4 presented complete chimerism with D1S80, DxS52, FVW and YNZ-22; case 5 with APO-B; case 10 with APO-B, 33.6 and YNZ-22; and case 12 with APO-B, D1S80, 33.6, YNZ-22 and SRY.

Evaluation using the SRY primer on female recipients with male donors enabled analysis on four cases and documented complete chimerism in three of them (cases 6,11 and 12). On the other hand, in case 9, this marker and other markers were not evaluated on day 30 but, as mentioned earlier, XY-FISH documented complete chimerism on day 60 .

With regard to male recipients with female donors, the SRY marker did not give information for analyzing chimerism, because all these recipients had the $Y$ chromosome, regardless of the time at which they were examined and regardless of the outcome of complete chimerism diagnosed using XY-FISH.

Thirteen patients were analyzed using XY-FISH. Of these, four were female recipients (\# 6, 9, 11 and 12) and seven were male (\# 1, 2, 3, $5,6,7,8,10$ and 13). This was the most sensitive method, and it allowed evaluation of chimerism in patients 1, 3, 2, 9 and 13, who had not been investigated regarding DNA prior to transplantation. From the SRY marker, it was seen that the female recipients kept the male Y chromosome, thus leading to an interpretation of complete chimerism, in combination with the XY-FISH probe results.

\section{DISCUSSION}

The resolution found using APO-B was 10/16 (62.5\%). It was noteworthy in relation to this set of primers that cases 5, 16 and 21 only had the APO-B primer as a marker for chimerism. Stuppia et al. ${ }^{25}$ documented resolution in $25 \%$ of Caucasian pairs using D1S80. According to Martinelli et al., ${ }^{20}$ D1S80 was the main marker in their cases with resolution of $6 / 6$ cases. Muniz et al. ${ }^{31}$ found $66 \%$ resolution. In our series, amplification occurred in $88 \%$ of the cas-

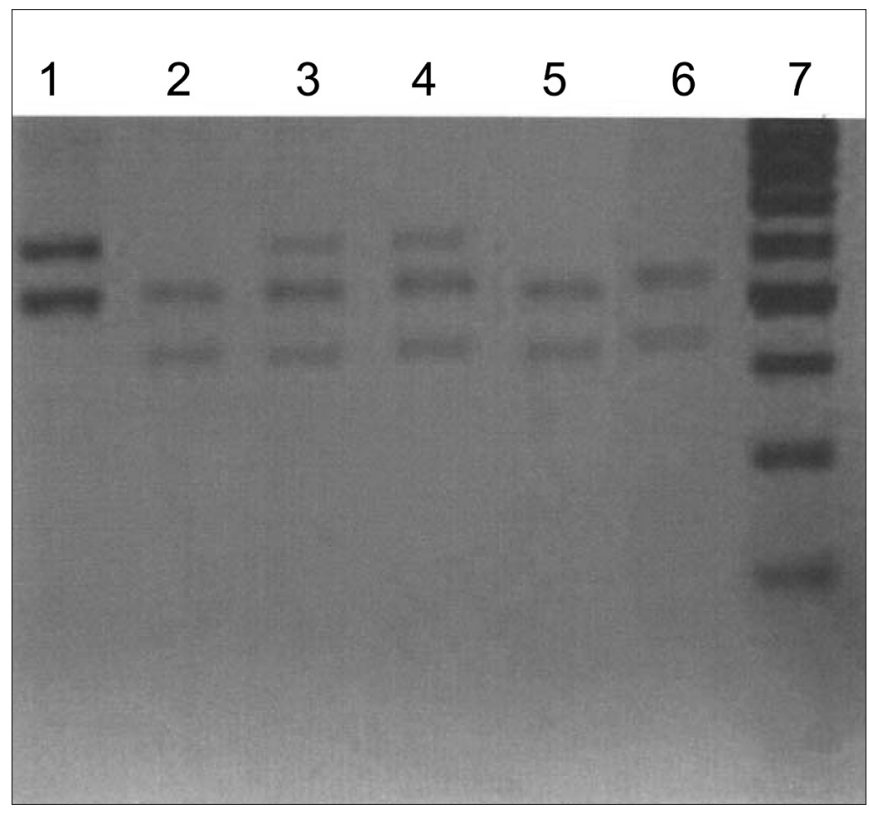

Figure 1. Evaluation using $2 \%$ agarose gel electrophoresis marker D1S80 following polymerase chain reaction (PCR) amplification (variable number of tandem repeats, VNTR technique) in case 7. (1) donor product; (2) patient product before transplantation; (3) and (4) donor and patient products after transplantation; (5) and (6) patient products after transplantation and after molecular relapse; (7) 100-base pair marker.

es (15 pairs) and resolution in 10/15 (75\%). We emphasize the fact that $5 / 17$ patients $(29 \%)$ presented resolution using the APO-B and D1S80 primers, but when we summed the separate results, combining them for both primers, there was information on 15 of the 17 pairs $(88 \%)$. Thus, combination of these two primers had great applicability in our series.

DxS52 was investigated by Stuppia et al., ${ }^{25}$ and they obtained resolution in $4 / 6$ cases $(66.6 \%)$. There was successful amplification of the DNA fragment from $11 / 17$ pairs (64\%), at different times after transplantation, but the degree of resolution among our patients was $4 / 11$ (36\%), i.e. lower than that described by Stuppia et al..$^{25}$

FVW was analyzed in relation to 35 pairs by Muniz et al. ${ }^{31}$ and resolution was detected in 15 (43\%). In our series, despite the success of amplification in relation to $14 / 17$ patients (82\%), there was resolution in only $2 / 14$ (14\%). This was also seen with $\mathrm{H}$-ras, which gave information only in the case of one patient (case 17), and there was difficulty in amplification in $11 / 17$ cases (65\%). Our data for $\mathrm{H}$-ras therefore differ from those of Hassan et al., ${ }^{30}$ who observed $36 \%$ resolution in cases of aplastic anemia, and were closer to the data of van Leeuwen et al., ${ }^{32}$ who found resolution relating to only $11 \%$ of 37 pairs.

We succeeded in amplifying YNZ-22 in 15/17 pairs (88.8\%), and the resolution was $7 / 15$ (47\%). Hassan et al. ${ }^{30}$ found that the resolution of this primer was $50 \%$, among individuals with aplastic anemia. The 33.6 primer gave information in relation to $40 \%$ (4/10), and this percentage was lower that described by Hassan et al. ${ }^{30}$

The resolution found for this panel of primers was as follows: D1S80, 10/15 patients (75\%); APO-B, 10/16 (62.5\%); YNZ-22, 7/15 (47\%); 33.6, 4/10 (40\%); DxS52, 4/11 (36\%); FVW, 2/14 
(14\%); and H-ras, 1/6 (16.6\%). YNZ-22 and FVW were easily amplified; YNZ-22 showed intermediate resolution, but FVW showed the lowest heterozygosity. We stress the importance of using larger numbers of primers in such panels, in order to achieve relevant results. Case 3 provides an example: this showed mixed chimerism through XY-FISH but the VNTR technique failed to show chimerism, since successful amplification of the APO-B, D1S80, DxS52, FVW and 33.6 primers showed homozygous bands. The importance of this panel was shown by the fact that patients 5, 15, 16, 20 and 21 presented only one primer marker. APO-B was the marker in cases 5, 16 and 21; D1S80 in case 15; and 33.6 in case 20.

The informativeness of each individual locus in VNTR/STR varies between different individuals and, therefore, the polymerase chain reaction products are of different lengths depending on the tandem repeats. Currently, DNA-based technologies are the methods of choice for chimerism analysis, mainly because of their sensitivity for detecting the presence of minor proportions of recipient clone cells after transplantation. Ariffin et al. ${ }^{4}$ evaluated individuals of Malay and Chinese ethnicity using two commercially-available forensic kits that are also widely used for multiplex and monoplex STR. In their cases, amplification and genotyping using this method revealed six out of 15 STR loci, which enabled resolution of 31 out of 33 cases (94\%): TH01 (73\%), VWA (73\%), FIA0I (52\%), CSFIPO (61\%), FESFPS (39\%) and TPOX (45\%). ${ }^{4}$ A combination of STR and VNTR markers tested by Talwar et al. ${ }^{3}$ in relation to hematopoietic stem cell transplantation cases and normal subjects in northern India demonstrated that the APOB'HVR, FES, VWA, D3S1358 and D16S310 loci were the most polymorphic of the 15 loci analyzed, with mean heterozygosity of $0.756 \pm 0.17$. A panel composed of these seven primers was able to differentiate $98.7 \%$ of the donor-recipient pairs out of the 77 settings tested. We emphasize that APO-B and D1S80 made resolution possible for $88 \%$ of our patients, but a larger population of both normal individuals and hematopoietic stem cell transplantation cases needs to be evaluated in order to reach a final conclusion.

The FISH XY probe was used in the cases of 13 patients, with the first sample on day 30 and the second concomitantly with the last collection for the VNTR technique. For four patients (1, 2, 9 and 13), no DNA analysis was performed prior to transplantation and although the VNTR technique showed homozygous bands, the final chimerism analysis was certified by means of XY-FISH.

The sensitivity of the XY-FISH method ranges from 0.7 to $5 \% .^{6}$ Two out of four patients had FISH values of 99 and $99.5 \%$ on day 30 (cases 4 and 10, respectively). In case 4, the D1S80, DxS52, FVW and YNZ-22 primers showed qualitative results with complete chimerism and in case 10, the APO-B, 33.6 and YNZ-22 primers presented equal results. Both of these patients displayed complete chimerism in subsequent evaluations, on days 60,90,120,180 and 360 in case 10 and on all these occasions plus day 1200 in case 4 . For patients 5 and 12, XYFISH showed that the proportions of donor cells were 97 and $97.5 \%$, respectively, in the evaluation on day 30 . Patient 5 only had the APO-B primer as a marker, while patient 12 had APO-B, D1S80, 33.6 and YNZ-22. On day 30, both of these patients presented complete chimerism. Further evaluations, which continued until day 180 for patient
12 and until day 120 for patient 5, documented complete chimerism according to the VNTR technique. For these two patients, XY-FISH at the last evaluation was also compatible with complete chimerism. In all the other evaluations using the XY probe, totaling 19 simultaneous analyses, the degree of chimerism was coincident with the results for primer markers using the VNTR technique, which included the interpretation of day 30 for cases 4 and 10 . From these results, it can be concluded that the XY probe, as assessed using FISH, which is feasible only for sex-unmatched pairs, is a more sensitive method than the VNTR technique, especially for early assessments following transplantation. Thus, for the NMA-HSCT technique, XY-FISH is important because of its outstanding capability for determining whether or not to perform donor lymphocyte infusion (DLI) in order to obtaining complete chimerism.

It should be noted that the analysis of hematopoietic chimerism using the XY probe does not depend on data collection prior to transplantation, as does the VNTR interpretation. The interpretation of XY probe data is quantitative and more decisive than is the qualitative or semiquantitative assessment of VNTR data. Today, single nucleotide polymorphism, STR and Y-chromosome-specific sequences analyzed by polymerase chain reactions (PCR) are the best methods for carrying out a quantitative evaluation of chimerism. Koldehoff et al. ${ }^{11}$ reported that single nucleotide polymorphism using 10 different gene loci discriminated patient cells from donor cells in 125 out of 135 pairs (93\%), while STR performed with 11 different genes resulted in accurate donor-host discrimination in all pairs. The results from the two methods were $74 \%$ concordant, but the single nucleotide technique detected mixed chimera earlier than STR did, thus enabling earlier interventions. Using a multivariate Cox model, this method was the only significant factor predicting relapse.

Studies on chimerism are of fundamental importance for the final diagnosis to explain why rejection occurs and for clarifying the etiology of hypoplasia following transplantation and any recurrences of the underlying disease. In this study, we evaluated the presence of SRY using normal controls consisting of male and female individuals who had not undergone transplantation. We observed four cases of female recipients with male donors, showing complete chimerism according to XY-FISH. This result was identical to that obtained through analysis of SRY in the DNA of blood cells. Meanwhile, seven male patients with female donors presented complete chimerism according to XYFISH, but they were positive for SRY, from evaluation of the DNA of their blood cells. The control that we used in each amplification reaction was DNA from normal males and females, but even if different samples were evaluated at different times, the results from these patients were always convergent using the SRY technique and divergent using the FISH technique. Koldehoff et al. ${ }^{11}$ analyzed the status of male recipients with female donors in 580 samples from 134 patients, using a quantitative real-time polymerase chain reaction (RT-PCR) on Y-chromosome specific sequences. They compared the results with interphasic XY-FISH and demonstrated the presence of mixed chimerism without signs of relapse in 35\% of the samples. Otherwise, the quantities of Y-DNA detected were low, compared with the amounts detected in 104 samples from relapsed leukemia patients at the time of 
analysis. Importantly, the amount of host DNA increased sequentially in relapsed patients, thereby proving that mixed chimerism becomes enhanced and possibly predicts relapse (which occurred after approximately 143 days in this study). The results were concordant with XYFISH findings in $73 \%$ of the patients. However, XY-FISH detected relapses only in 12 settings and Y-chromosome polymerase chain reactions detected 36, by means of sequential evaluation of mixed chimerism. Based on our results, we ruled out the use of quantitative methods for evaluating chimerism in male recipients using the SRY primer, and the results must be interpreted with caution.

\section{CONCLUSION}

1. The VNTR technique enabled evaluation of chimerism in 17 out of 21 patients, and the primers used presented the following resolution: APO-B (62.5\%), D1S80 (75\%), DxS52 (36\%), FWF (14\%), 33.6 (40\%), YNZ-22 (47\%) and H-ras (16.6\%).

2. The XY-FISH technique, which was used for 13 cases in which the donor and recipient were of different genders, showed quantitative resolution of chimerism in $100 \%$ of cases.

3. In two patients, mixed chimerism was identified. In these pairs, there were discrepancies in the assessment of chimerism on day 30 between the XY-FISH and VNTR techniques. XY-FISH identified $95 \%$ and $97 \%$ mixed chimerism and the VNTR technique showed complete chimerism at this stage of the procedure. In other patients and at other times, the two methods were coincident.

4. The SRY primer proved to be capable of resolution only in cases of female recipients when their results were coincident with those from XY-FISH.

5. When the APO-B and D1S80 primers were considered in the pan$\mathrm{el}$, this enabled resolution of chimerism in 15 out of 17 patients $(88 \%)$.

\section{REFERENCES}

1. Sreenan JJ, Pettay JD, Tbakhi A, et al. The use of amplified variable number of tandem repeats (VNTR) in the detection of chimerism following bone marrow transplantation. A comparison with restriction fragment length polymorphism (RFLP) by Southern blotting. Am J Clin Pathol. 1997;107(3):292-8.

2. Antin JH, Childs R, Filipovich AH, et al. Establishment of complete and mixed donor chimerism after allogeneic lymphohematopoietic transplantation: recommendations from a workshop at the 2001 Tandem Meetings of the International Bone Marrow Transplant Registry and the American Society of Blood and Marrow Transplantation. Biol Blood Marrow Transplant. 2001;7(9):473-85.

3. Talwar S, Khan F, Nityanand S, Agrawal S. Chimerism monitoring following allogeneic hematopoietic stem cell transplantation. Bone Marrow Transplant. 2007;39(9):529-35.

4. Ariffin H, Daud SS, Mohamed Z, Ibrahim K, Lee TF, Chong LA. Evaluation of two short tandem repeat multiplex systems for post-haematopoietic stem cell transplantation chimerism analysis. Singapore Med J. 2007;48(4):333-7.

5. Mackinnon S, Papadopoulos EB, Carabasi MH, et al. Adoptive immunotherapy evaluating escalating doses of donor leukocytes for relapse of chronic myeloid leukemia after bone marrow transplantation: separation of graft-versus-leukemia responses from graft-versushost disease. Blood. 1995;86(4):1261-8.

6. Khan F, Agarwal A, Agrawal S. Significance of chimerism in hematopoietic stem cell transplantation: new variations on an old theme. Bone Marrow Transplant. 2004;34(1):1-12.
7. Hibi S, Tsunamoto $\mathrm{K}$, Todo $\mathrm{S}$, et al. Chimerism analysis on mononuclear cells in the CSF after allogeneic bone marrow transplantation. Bone Marrow Transplant. 1997;20(6): 503-6.

8. Dewald G, Stallard R, Al Saadi A, et al. A multicenter investigation with interphase fluorescence in situ hybridization using $X$ - and Y-chromosome probes. Am J Med Genet. 1998;76(4):318-26.

9. Lui YY, Chik KW, Chiu RW, Ho CY, Lam CW, Lo YM. Predominant hematopoietic origin of cellfree DNA in plasma and serum after sex-mismatched bone marrow transplantation. Clin Chem. 2002;48(3):421-7.

10. Sufliarska S, Minarik G, Horakova J, et al. Establishing the method of chimerism monitoring after allogeneic stem cell transplantation using multiplex polymerase chain reaction amplification of short tandem repeat markers and Amelogenin. Neoplasma. 2007;54(5): 424-30.

11. Koldehoff M, Steckel NK, Hlinka M, Beelen DW, Elmaagacli AH. Quantitative analysis of chimerism after allogeneic stem cell transplantation by real-time polymerase chain reaction with single nucleotide polymorphisms, standard tandem repeats, and Y-chromosomespecific sequences. Am J Hematol. 2006;81(10):735-46.

12. McSweeney PA, Storb R. Mixed chimerism: preclinical studies and clinical applications. Biol Blood Marrow Transplant. 1999;5(4):192-203.

13. Storb R, Yu C, Zaucha JM, et al. Stable mixed hematopoietic chimerism in dogs given donor antigen, CTLA4lg, and $100 \mathrm{cGy}$ total body irradiation before and pharmacologic immunosuppression after marrow transplant. Blood. 1999;94(7):2523-9.

14. Bosi A, Bartolozzi B, Guidi S. Allogeneic stem cell transplantation. Transplant Proc 2005;37(6):2667-9.

15. Giralt S. Allografting older patients--myths and realities. Biol Blood Marrow Transplant 2009;15(1 Suppl):146-8.

16. Khouri IF, Keating M, Körbling M, et al. Transplant-lite: induction of graft-versus-malignancy using fludarabine-based nonablative chemotherapy and allogeneic blood progenitorcell transplantation as treatment for lymphoid malignancies. J Clin Oncol. 1998;16(8): 2817-24.

17. Slavin S, Nagler A, Naparstek E, et al. Nonmyeloablative stem cell transplantation and cell therapy as an alternative to conventional bone marrow transplantation with lethal cytoreduction for the treatment of malignant and nonmalignant hematologic diseases. Blood. 1998;91(3):756-63.

18. Slavin S. New strategies for bone marrow transplantation. Curr Opin Immunol 2000;12(5):542-51.

19. Tsirigotis P, Bitan RO, Resnick IB, et al. A non-myeloablative conditioning regimen in allogeneic stem cell transplantation from related and unrelated donors in elderly patients. Haematologica. 2006;91(6):852-5.

20. Martinelli G, Trabetti E, Farabegoli P, et al. Early detection of bone marrow engraftment by amplification of hypervariable DNA regions. Haematologica. 1997;82(2):156-60.

21. Smith AG, Martin PJ. Analysis of amplified variable number tandem repeat loci for evaluation of engraftment after hematopoietic stem cell transplantation. Rev Immunogenet. 1999;1(2):255-64.

22. Kraus G, Geffin R, Spruill G, et al. Cross-clade inhibition of HIV-1 replication and cytopathology by using RNase P-associated external guide sequences. Proc Natl Acad Sci U S A. 2002;99(6):3406-11.

23. Richards B, Heilig R, Oberlé I, Storjohann L, Horn GT. Rapid PCR analysis of the St14 (DXS52) VNTR. Nucleic Acids Res. 1991;19(8):1944.

24. Siva SC, Johnson SI, McCracken SA, Morris JM. Evaluation of the clinical usefulness of isolation of fetal DNA from the maternal circulation. Aust N Z J Obstet Gynaecol. 2003;43(1):10-5

25. Stuppia L, Calabrese G, Di Bartolomeo P, et al. Retrospective investigation of hematopoietic chimerism after BMT by PCR amplification of hypervariable DNA regions. Cancer Genet Cytogenet. 1995;85(2):124-8.

26. Peake IR, Bowen D, Bignell P, et al. Family studies and prenatal diagnosis in severe von Willebrand disease by polymerase chain reaction amplification of a variable number tandem repeat region of the von Willebrand factor gene. Blood. 1990;76(3):555-61.

27. Ugozzoli L, Yam P, Petz LD, et al. Amplification by the polymerase chain reaction of hypervariable regions of the human genome for evaluation of chimerism after bone marrow transplantation. Blood. 1991;77(7):1607-15.

28. Boerwinkle E, Xiong WJ, Fourest $E$, Chan L. Rapid typing of tandemly repeated hypervariable Ioci by the polymerase chain reaction: application to the apolipoprotein B 3' hypervariable region. Proc Natl Acad Sci U S A. 1989;86(1):212-6.

29. Budowle B, Chakraborty R, Giusti AM, Eisenberg AJ, Allen RC. Analysis of the VNTR locus D1S80 by the PCR followed by high-resolution PAGE. Am J Hum Genet. 1991;48(1) 137-44. 
30. Hassan $\mathrm{R}$, Bonamino $\mathrm{MH}$, Braggio $\mathrm{E}$, et al. A systematic approach to molecular quantitative determination of mixed chimaerism following allogeneic bone marrow transplantation: an analysis of its applicability in a group of patients with severe aplastic anaemia. Eur J Haematol. 2004;73(3):156-61.

31. Muniz ES, Plassa F, Amselem S, Goossens M, Vernant JP. Molecular analysis of polymorphic loci to study chimerism after allogeneic bone marrow transplantation. Heteroduplex analysis in denaturing gradient gel electrophoresis: a new approach to detecting residual host cells. Transplantation. 1994;57(3):451-6.

32. van Leeuwen JE, van Tol MJ, Bodzinga BG, et al. Detection of mixed chimaerism in flowsorted cell subpopulations by PCR-amplified VNTR markers after allogeneic bone marrow transplantation. Br J Haematol. 1991;79(2):218-25.

Sources of funding: Division of Hematology and Transfusion Medicine, Universidade Federal de São Paulo - Escola Paulista de Medicina (Unifesp-EPM), São Paulo, Brazil; and partial financial support from the Fundação de Amparo à Pesquisa do Estado de São Paulo (Fapesp), Grant nos. 02/09994-4 and 02/10290-1
Conflict of interest: Not declared

Date of first submission: April 30, 2008

Last received: November 3, 2009

Accepted: November 4, 2009

Address for correspondence:

José Salvador Rodrigues Oliveira

Departamento de Medicina, Divisão de Hematologia

Universidade Federal de São Paulo - Escola Paulista de Medicina

Rua Botucatu, 740 - 3o andar

Vila Clementino - São Paulo (SP) - Brasil

CEP 04023-900

Tel. (+55 11) 5576-4237/5576-4240

Fax. (+55 11) 5571-8806

E-mail: salvador@hemato.epm.br 